\title{
Mixed Epithelial and Stromal Tumor of the Kidney : A Case Report
}

\begin{abstract}
The descriptive term "mixed epithelial and stromal tumor of the kidney" was recently proposed for a group of renal tumors characterized histologically by a mixture of stromal and epithelial proliferation. It is a rare benign neoplasm of the kidney which has been reported under various names such as adult type mesoblastic nephroma or others. We report a case of mixed epithelial and stromal tumor in a $47 \mathrm{yr}$ old female patient presenting as a partly cystic and partly solid renal mass. Microscopically, the tumor exhibited spindle cell component in solid portion and epithelial proliferation around microcystic areas. Immunoreactive profiles and ultrastructural examination suggested myofibroblastic nature of the stromal cells. We believe this case exemplifies a unique adult renal tumor displaying both epithelial and stromal neoplastic component and has a few unusual features worthy of attention.
\end{abstract}

Key Words : Kidney; Nephroma, Mesoblastic; Adult

\section{Ji-Eun Kwon, Joo-Hyung Kang, Ghee Young Kwon}

Department of Pathology, Samsung Medical Center Sungkyunkwan University School of Medicine, Seoul, Korea

Received : 23 September 2005

Accepted : 15 November 2005

\section{Address for correspondence}

Ghee Young Kwon, M.D.

Department of Pathology, Samsung Medical Center,

50 Ilwon-dong. Gangnam-gu, Seoul 135-710, Korea

Tel : +82.2-3410-2770, Fax: +82.2-3410-0025

E-mail : geeo@smc.samsung.co.kr

\section{INTRODUCTION}

Over the past few years, there has been recognition of a distinctive group of renal tumors composed grossly of cystic and solid portion and microscopically of stromal and epithelial proliferation. While it is not clear whether they represent a heterogenous group or a single disease entitiy, these tumors have been reported under various names such as adult mesoblastic nephroma, cystic nephroma, mixed epithelial and stromal tumor and some others. We believe that the descriptive and unifying term of mixed epithelial and stromal tumor is appropriate for this group of tumors until further characterization is made and report a case of renal tumor which appears to represent a good example of this entity.

\section{CASE REPORT}

A 47-yr-old woman was detected to harbor a right renal mass by ultrasonography on routine examination. Microscopic hematuria was also present at that time but there were no other abnormal clinical or laboratory findings or past history of medical problem. On computed tomography, the mass measured $7 \mathrm{~cm}$ in the largest dimension and was multiseptated with irregularly enhancing solid component (Fig. 1). Radical nephrectomy was performed under the diagnosis of renal cell carcinoma. The mass was occupying mid to lower pole of the right kidney close to renal sinus and partially pro- truding into renal pelvis. It measured $8 \times 6 \mathrm{~cm}$ and was largely cystic with a whitish yellow solid mural nodule of $3 \times 3$ $\mathrm{cm}$ (Fig. 2) and there was no involvement of ureter or blood vessels. Microcystic lesions were present with regional spongelike appearance and focal calcification was also found. Upper half of renal parenchyma uninvolved by the mass was grossly unremarkable. Microscopically, solid portion was composed of irregularly arranged bundles of cigar-shaped spindle cells sprinkled with a few inflammatory cells in the fibrillar background (Fig. 3). Cellular atypia was negligible and mitosis was not encountered. The nodule of spindle cells displayed hypocelluar areas at the periphery entrapping several tubular structures which occasionally exhibited cyst-like dilatation. Epithelial proliferation was exuberant around the spongelike areas and occupied an area measuring approximately 1.5 $\mathrm{cm}$ in largest dimension. Eosinophilic columnar epithelial cells containing occasional single unconspicuous nucleolus constituted papillary structures with fibrovascular core and intervening foamy histiocytes (Fig. 4). Immunohistochemically, the spindle cells were positive for vimentin, smooth muscle actin, but negative for CD34, desmin, HMB45, estrogen receptor and progesterone receptor while epithelial cells were reactive for epithelial membrane antigen, high molecular weight cytokeratin and pancytokeratin. On electron microscopic examination, the spindle cells had many subplasmalemmal pinocytotic vesicles and intracytoplasmic filaments occasionally forming dense bodies, thus suggesting myofibroblastic differentiation (Fig. 5). 


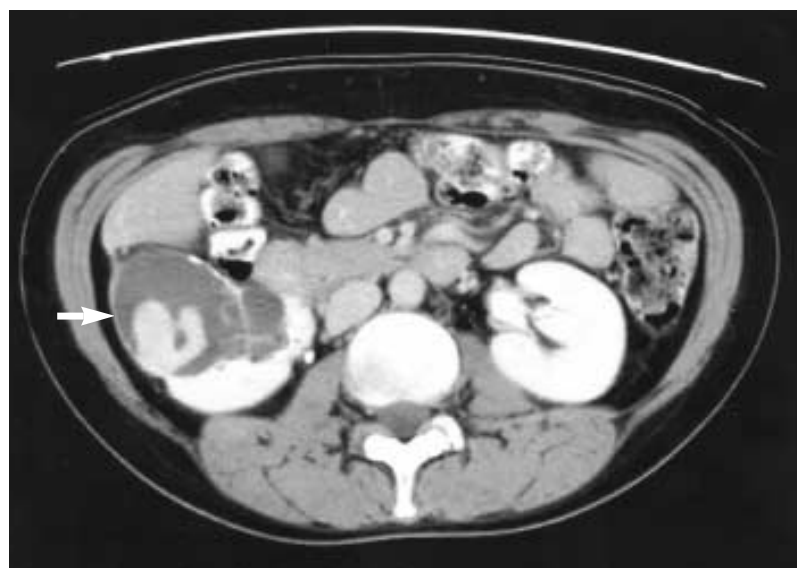

Fig. 1. Contrast-enhanced CT shows a well-enhancing solid component within the multiseptated cystic lesion arising from the right kidney (arrow). The lesion also has multifocal calcifications in the cystic wall.

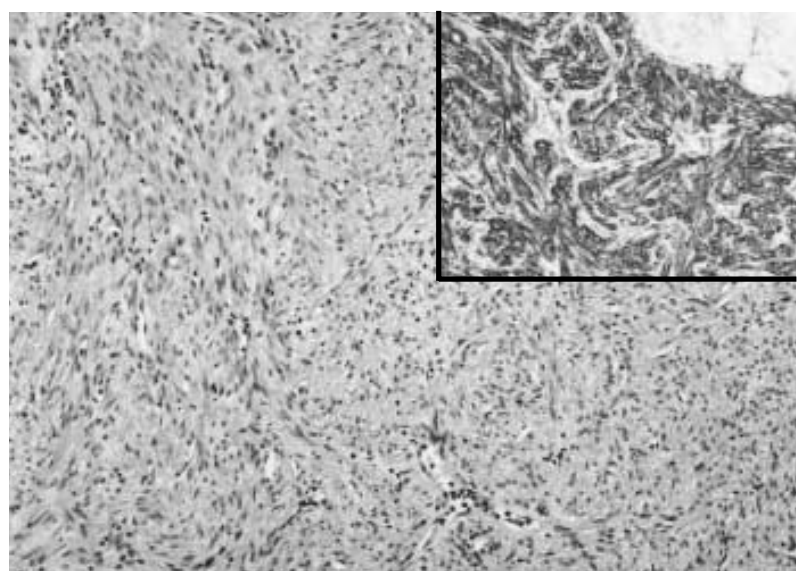

Fig. 3. Grossly solid portion displays spindle cells in the fibrillar background $(H \& E, \times 100)$. (Inset) The cells are reactive for smooth muscle actin $(\times 100)$.

\section{DISCUSSION}

Michal and Syrucek first proposed the term of mixed epithelial and stromal tumor of the kidney in 1998 (1) and later Adsay et al. reported a group of 12 patients under the same name and regarded the diagnosis as an appropriate preliminary title for that category of tumor which is characterized grossly by a mixture of solid and cystic areas and is microscopically composed of proliferations of stromal and epithelial cells (2). Various diagnoses have been rendered to tumors with similar morphologic findings such as adult mesoblastic nephroma (3-6), cystic hamartoma of pelvis (7), cystic nephroma (8) or mature nephroblastic tumor and cystic partially differentiated nephroblastoma (9). It remains to be determined whether these tumors are comprised of a heterogenous group of tumors or represent one distinct entity. However, these tumors basically share similar clinicopathologic char-

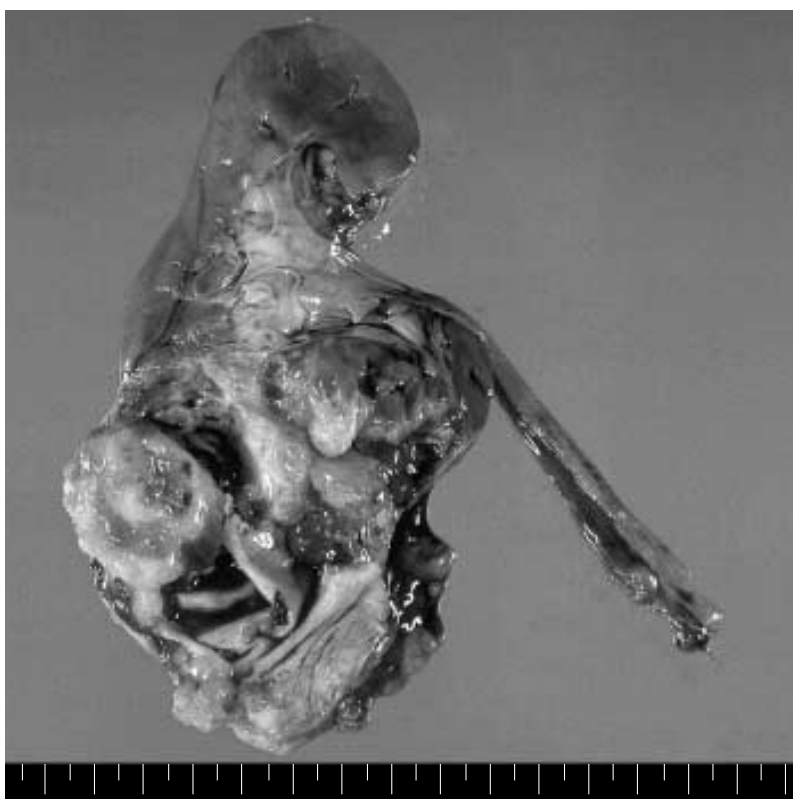

Fig. 2. A largely cystic mass is found in the mid to lower pole of the kidney and contains an eccentric solid nodule.

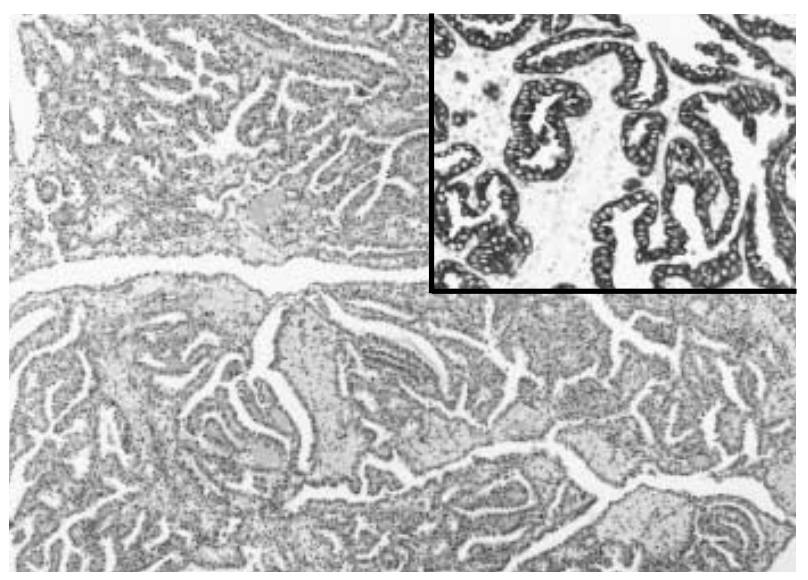

Fig. 4. Around the microcystic component, florid epithelial proliferation is found which assume papillary configuration with intervening foamy histiocytes $(\mathrm{H \& E}, \times 40)$. (Inset) The epithelial cells are positive for pancytokeratin $(\times 100)$.

acteristics and therefore it appears reasonable, at least for the present, to regard them as a single entity.

Approximately 50 cases of such tumors have been reported in the literature (2-5) and three cases have been documented in Korean literature under the name of adult mesoblastic nephroma (10-12). Common clinical presentations were those of usual renal mass lesions such as flank pain, hematuria, symptoms of infection or no attributable symptoms. Mean tumor size is approximately $6 \mathrm{~cm}$ and the tumor shows a female preponderance centered around perimenopausal age and frequent reactivity for estrogen or progesterone receptors. And in rare reported cases of male patients, there was a history of 


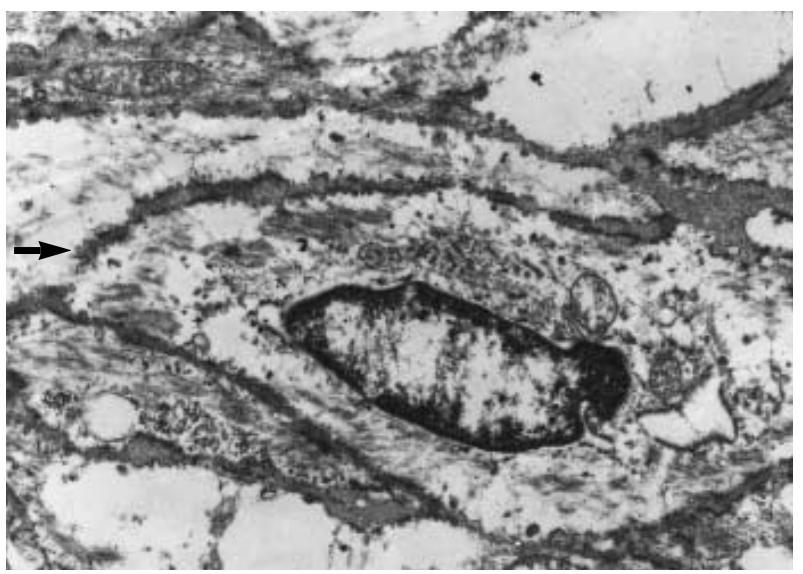

Fig. 5. Electron microscopic examination from solid area reveals spindle-shaped tumor cells showing many subplasmalemmal pinocytotic vesicles (arrow) and intracytoplasmic filaments occasionally forming dense bodies $(\times 10,000)$.

hormone therapy (2). These facts led to the suggestion of hormonal mechanism in pathogenesis and the estrogen- and progesterone-receptor positivity are sometimes deemed sufficient characteristics to warrant its utility as an adjunct diagnostic criteria for this tumor. However, our case lacked evidence of hormonal receptor expression and therefore it is reasonable to conclude that not all cases of mixed epithelial and stromal tumor implicate hormonal mechanism in pathogenesis and it also can be speculated that this presumed difference in pathogenesis might eventually result in subclassification of this tumor after accumulation of further data.

The stromal component of mixed epithelial and stromal tumor varies in cellularity and can assume various histologic appearance reminiscent of leiomyoma, solitary fibrous tumor or ovarian stroma. Ovarian stroma, frequently found in mixed epithelial and stromal tumor, is absent in this case, which might be related to estrogen and progesterone receptor negativity of this case.

Epithelial proliferation in this case is exuberant and spans an area over $1 \mathrm{~cm}$ in diameter. This feature is worrisome especially when we consider the newly accepted criteria of $0.5 \mathrm{~cm}$ as a cut-off point between papillary adenoma and carcinoma (13). However, malignancy of epithelial component is not yet documented in mixed epithelial and stromal tumor whereas there is a report of stromal malignancy (14). Therefore, while it appears reasonable to accept, at least for the present, that benign epithelial proliferation can be florid, the possibility cannot be completely ruled out that there might develop epithelial malignancy.

Adult mesoblastic nephroma was first reported in 1973 (15) and was the primary diagnosis in a majority of this group of tumors (3-6). While it is clear that this tumor shares a few morphologic characteristics of congenital mesoblastic nephroma, it also appears evident that there are a few unmistakable differences. Firstly and most importantly, the epithelial pro- liferation seems an integral neoplastic component in this tumor (2) whereas in congenital mesoblastic nephroma, it is more likely entrapped epithelial portion with occasional metaplastic changes and focal hyperplasia. Furthermore, genetic alterations typical of congential mesoblastic nephroma were not found in this tumor (16). And frequent infiltration into surrounding renal parenchyma found in congenital mesoblastic nephroma is rarely encountered (4). Therefore this tumor is more likely unrelated to mesoblastic nephroma and it appears more reasonable to apply the descriptive term of mixed epithelial and stromal tumor at least for the present under which name it is included in the current WHO classification (13).

When we accept the entity of mixed epithelial and stromal tumor, the differential diagnosis is limited. The spindle cell component of mixed epithelial and stromal tumor can be found in solitary fibrous tumor (17) or angiomyolipoma (18), both of which can be excluded with immunostaining and by lack of epithelial proliferation. Biphasic renal lesions may encompass tumors such as nephroblastoma, cystic partially differentiated nephromablastoma and cystic embryonal sarcoma (19), all of which are rare in adulthood or contain malignant mesenchymal component. Rare benign biphasic renal tumor such as nephrogenic adenofibroma (20) can be differentiated on the basis of negative immunoreactivity to actin or desmin and the lack of cystic component.

In summary, we report a case of renal tumor showing unique histologic features of biphasic epithelial and stromal component and briefly discuss the differential diagnosis and its relationship with mesoblastic nephroma.

\section{REFERENCES}

1. Michal M, Syrucek M. Benign mixed epithelial and stromal tumor of the kidney. Pathol Res Pract 1998; 194: 445-8.

2. Adsay NV, Eble JN, Srigley JR, Jones EC, Grignon DJ. Mixed epithelial and stromal tumor of the kidney. Am J Surg Pathol 2000; 24: 958-70.

3. Durham JR, Bostwick DG, Farrow GM, Ohorodnik JM. Mesoblastic nephroma of adulthood. Report of three cases. Am J Surg Pathol 1993; 17: 1029-38.

4. Truong LD, Williams R, Ngo T, Cawood C, Chevez-Barrios P, Awalt HL, Brown RW, Younes M, Ro JY. Adult mesoblastic nephroma: expansion of the morphologic spectrum and review of literature. Am J Surg Pathol 1998; 22: 827-39.

5. Trillo AA. Adult variant of congenital mesoblastic nephroma. Arch Pathol Lab Med 1990; 114: 533-5.

6. Daniel L, Lechevallier E, Bouvier C, Coulange C, Pellissier JF. Adult mesoblastic nephroma. Pathol Res Pract 2000; 196: 135-9.

7. Pawade J, Soosay GN, Delprado W, Parkinson MC, Rode J. Cystic hamartoma of the renal pelvis. Am J Surg Pathol 1993; 17: 1169-75.

8. Aoyagi T, Kakudo K, Satoh S, Hata J, Shiramizu M, Tamaoki N. Multilocular cystic nephroma in an adult: immunohistochemical 
study. J Urol 1987; 138: 397-9.

9. Nagao T, Sugano I, Ishida Y, Tajima Y, Masai M, Nagakura K, Matsuzaki O, Kondo Y, Nagao K. Cystic partially differentiated nephroblastoma in an adult: an immunohistochemical, lectin histochemical and ultrastructural study. Histopathology 1999; 35: 65-73.

10. Lee HS, Jeong YY, Choi S, Kang HK. Calcified mesoblastic nephroma in an adult: a case report. J Korean Radiol Soc 2002; 46: 247-9.

11. Lim CS, Lee KH, Seong DH, Lee T, Yoon SM. A case of mesoblastic nephroma in adulthood. Korean J Nephrol 2000; 19: 1163-7.

12. Koo JH, An HJ, Lee CK, Rhew HY. A case of mesoblastic nephroma of kidney in adult. Korean J Urol 1999; 40: 1566-8.

13. Eble JN, Sauter G, Epstein JI, Seseterhehn IA, eds. World Health Organization Classification of Tumours. Tumors of the Urinary system and Male Genital Organs. Lyon: IARC Press, 2004.

14. Nakagawa T, Kanai Y, Fujimoto H, Kitamura H, Furukawa H, Maeda S, Oyama T, Takesaki T, Hasegawa T. Malignant mixed epithelial and stromal tumours of the kidney: a report of the first two cases with a fatal clinical outcome. Histopathology 2004; 44: 302-4.

15. Block NL, Grabstald HG, Melamed MR. Congenital mesoblastic nephroma (leiomyomatous hamartoma): first adult case. J Urol 1973; 110: 380-3.

16. Pierson CR, Schober MS, Wallis T, Sarkar FH, Sorensen PH, Eble JN, Srigley JR, Jones EC, Grignon DJ, Adsay V. Mixed epithelial and stromal tumor of the kidney lacks the genetic alterations of cellular congenital mesoblastic nephroma. Hum Pathol 2001; 32: 51320.

17. Wang J, Arber DA, Frankel K, Weiss LM. Large solitary fibrous tumor of the kidney: report of two cases and review of the literature. Am J Surg Pathol 2001; 25: 1194-9.

18. Stone CH, Lee MW, Amin MB, Yaziji H, Gown AM, Ro JY, Tetu B, Paraf F, Zarbo RJ. Renal angiomyolipoma: further immunophenotypic characterization of an expanding morphologic spectrum. Arch Pathol Lab Med 2001; 125: 751-8.

19. Delahunt B, Beckwith JB, Eble JN, Fraundorfer MR, Sutton TD, Trotter GE. Cystic embryonal sarcoma of kidney: a case report. Cancer 1998; 82: 2427-33.

20. Hennigar RA, Beckwith JB. Nephrogenic adenofibroma. A novel kidney tumor of young people. Am J Surg Pathol 1992; 16: 325-34. 